\title{
Patogénesis de vitíligo. Teoría autoinmune
}

\author{
Pathogenesis of vitiligo. Autoimmune theory \\ Germán Guerrero Oliva, ${ }^{*}$ Ximena Trejo Ortega, ${ }^{*}$ María Luisa Peralta Pedrero, ${ }^{*}$ \\ Gibrán Pérez Montesinos, ${ }^{*}$ Martha Alejandra Morales Sánchez, ${ }^{*}$ Fermín Jurado Santa Cruz ${ }^{\star}$
}

\section{RESUMEN}

El vitíligo se considera la discromía adquirida más frecuente, representa de 2 a $4 \%$ de la consulta dermatológica en México, siendo éste uno de los países con mayor incidencia. Comprender los mecanismos por los cuales ocurre la eliminación de los melanocitos, implica diferentes enfoques. El vitíligo es un trastorno complejo, multifactorial, no pueden aplicarse los mismos mecanismos patogénicos en todos los casos y diferentes vías patogénicas podrían participar simultáneamente. El presente trabajo tiene como finalidad mostrar el panorama general que se tiene respecto a la teoría inmunológica del vitíligo. Se abordan factores desencadenantes intrínsecos y extrínsecos, procesos celulares, participación de las especies reactivas de oxígeno, participación del sistema inmunológico y su relación con otras enfermedades. Además, se incluyen las bases genéticas y ambientales que se ha observado interactúan en la muerte de los melanocitos. Se recopiló información sobre las diferentes líneas de investigación en las cuales se continúa trabajando para conocer más sobre la patogénesis de esta enfermedad.

Palabras clave: Inmunología, vitíligo, patogénesis, estrés oxidativo.

\section{ABSTRACT}

Vitiligo is considered the most frequent acquired dyschromia, causing 2 to $4 \%$ of the dermatological consultation in Mexico, being this one of the countries with the highest incidence. Understanding the mechanisms by which melanocyte loss occurs is a fragmented approach, it is a complex, multifactorial disorder, the same causal mechanisms cannot have problems in all cases, and different pathogenic mechanisms can work together, the present work has as its objective to show the overall picture that it has regarding the immunological theory of vitiligo, intrinsic and extrinsic triggers are addressed, cellular processes, participation of reactive oxygen species, participation of the immune system and its relationship with other diseases. The genetic and environmental bases that have been seen to interact in the death of melanocytes are also included, and information is collected on the different lines of research in which work continues to learn more about the pathogenesis of this disease.

Keywords: Immunology, vitiligo, pathogenesis, oxidative stress.

\section{INTRODUCCIÓN}

El vitíligo es la discromía adquirida más frecuente, se considera una leucodermia melanocitopénica, afecta de 0.5 a $2 \%$ de la población mundial. ${ }^{1}$ El país con la incidencia más alta es India con $8.8 \%$, a éste le siguen México y Japón. ${ }^{2}$ En México, el vitíligo ocupa entre el tercero y quinto lugar entre todas las dermatosis. Puede aparecer a cualquier edad; su mayor incidencia está entre los 10 y 30 años de edad, afecta a todas las razas, se presenta por igual en hombres y mujeres. Se caracteriza por presentar manchas acrómicas en la piel

* Área de Investigación del Centro Dermatológico «Dr. Ladislao de la Pascua». CDMX, México. y/o mucosas, ${ }^{3,4}$ en la mayoría de las manchas no hay melanocitos. ${ }^{5,6}$ Clínicamente puede afectar cualquier región corporal o distribuirse siguiendo los dermatomas, constituyendo las variedades no segmentaria o segmentaria, respectivamente.

Dependiendo de la actividad de la enfermedad se puede clasificar como progresivo o estable. ${ }^{6}$ De 2014 a 2016 en el Centro Dermatológico «Dr. Ladislao de la Pascua», $57 \%$ de los de los pacientes correspondieron al sexo femenino, la frecuencia observada en los subtipos para el vitíligo segmentario fue de $42.7 \%$ y para el no segmentario fue de $57.3 \%$. El vitíligo es

Citar como: Guerrero OG, Trejo OX, Peralta PML, Pérez MG, Morales SMA, Jurado SCF. Patogénesis de vitíligo. Teoría autoinmune. Rev Cent Dermatol Pascua. 2020; 29 (2-3): 61-76. https://dx.doi.org/10.35366/99918 
un trastorno complejo y multifactorial; es probable que participen de manera aislada o en conjunto diferentes mecanismos de daño. ${ }^{3,7}$ Se han postulado múltiples teorías para explicar la patogénesis del vitíligo y los mecanismos que finalmente conducen a la pérdida de melanocitos. Los mecanismos más importantes incluyen la predisposición genética, estado redox alterado sumado al daño de melanocitos (teoría bioquímica), ${ }^{8-13}$ respuesta simpática aumentada y daño de melanocitos mediado por catecolaminas/ neurotransmisores (teoría neural), y deterioro en la adhesión de melanocitos (melanocitorragia). ${ }^{14-19} \mathrm{La}$ combinación de éstos intenta explicar la patogénesis del vitíligo (teoría de la combinación o teoría integrada). ${ }^{20}$ La teoría autoinmune como mecanismo para la destrucción de los melanocitos es la más aceptada, la respaldan estudios epidemiológicos, clínicos, experimentales así como la asociación del vitíligo con otros trastornos autoinmunes. , $^{3,13,20-33}$

\section{VITÍLIGO Y GENÉTICA}

El vitíligo se considera una enfermedad con susceptibilidad genética con rasgos poligénicos, ${ }^{21,34-36}$ es más frecuente en los familiares de primer grado de los pacientes con vitíligo. ${ }^{23}$ Por estudios de asociación del genoma se han identificado aproximadamente 50 loci de susceptibilidad para el vitíligo, alrededor de $90 \%$ involucran inmunidad innata y adaptativa y $10 \%$ están relacionados con los antígenos de melanocitos y las vías de respuesta al estrés biológico. 3,13,27,29,37

Los loci de susceptibilidad que codifican para los componentes del sistema inmunológico innato son NLRP1, IFIH1 (MDA5), CASP7, C1QTNF6, inductor de interferón $\beta$ que contiene el dominio TIR (TRIF). ${ }^{38}$ Los loci de susceptibilidad del sistema inmunológico adaptativo se relacionan con: HLA clase I y II, PTPN22, IL2R $\alpha$, GZMB, FOXP3, BACH2, CD80 y CCR6, algunos de ellos se comparten con otros trastornos autoinmunes como diabetes tipo 1, enfermedad tiroidea y artritis reumatoide. ${ }^{39-43} \mathrm{El}$ papel clave de los antioxidantes en el vitíligo también ha sido sugerido por asociación de genes candidatos, se observó una asociación significativa entre el polimorfismo de nucleótido único (SNP) rs3565214 dentro de NRF2 y vitíligo. ${ }^{27}$

El polimorfismo del gen $\mathrm{CDH} 1$ que codifica $\mathrm{E}$ cadherina se estudió en el vitíligo, se concluyó que participa en el conjunto de elementos que dan origen al vitíligo y se asocia con comorbilidades autoinmunes. ${ }^{44}$ También el polimorfismo en la endonucleasa- 1 apirimidínica, una de las enzimas que repara el daño en el ADN puede predisponer el desarrollo del vitíligo. ${ }^{45} \mathrm{El}$ gen de la proteína de unión aXBP1 codifica un factor de transcripción que media la activación de la respuesta de proteínas desplegadas (UPR), como un locus de susceptibilidad para el vitíligo generalizado. $^{39,46-48}$

\section{FACTORES DESENCADENANTES}

Los elementos que participan en el daño autoinmune en el vitíligo son: los melanocitos, las células efectoras del sistema inmunológico y los desencadenantes ambientales. ${ }^{49}$ Varios estímulos exógenos y endógenos se han relacionado con la aparición de la enfermedad. ${ }^{23,42,50,51}$ Los estímulos exógenos que se involucran durante la exposición al medio ambiente son radiación UVA, UVB, rayos $X$, traumatismos, productos químicos citotóxicos como fenoles, monobenzona, orto y paraquinoles catecólicos que se encuentran en los tintes para el cabello, resinas/adhesivos y tirosina. Algunas enfermedades también tienen una participación activa en la exacerbación de vitíligo como las neoplasias malignas, infecciones graves, trastornos neurales, desequilibrio del calcio así como la aplicación de medicamentos, hormonas y vacunas; se ha relacionado también con el embarazo y el estrés psicógeno. ${ }^{45}$ Entre los estímulos endógenos en los melanocitos se consideran la síntesis de melanina, el metabolismo celular, la proliferación, la diferenciación, la apoptosis y las reacciones inmunológicas. . $13,20,30,45,52$ Se cree que los factores exógenos y endógenos inducen estrés oxidativo en los melanocitos como lo indican los altos niveles de especies reactivas de oxígeno (ERO) que se encuentran en la piel lesionada (principalmente peróxido de hidrógeno y peroxinitrito). ${ }^{8,13,30,45,52}$

Dentro de los factores endógenos, se ha observado que los melanocitos de pacientes con vitíligo tienen una incapacidad heredada para resolver el estrés celular, presentan anomalías intrínsecas y anomalías en las vías de transducción de señales, lo que los hace susceptibles a daño nuclear y de membrana, ${ }^{20,51,53}$ los datos anteriores son compatibles con una condición de senescencia prematura inducida por el estrés que afecta la melanogénesis, proliferación, diferenciación celular,

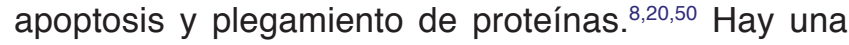
reducción en el factor de crecimiento de melanocitos y el factor de células madre, normalmente secretados por los queratinocitos. Los melanocitos también presentan mitocondrias anormales, compartimentación melanosómica anormal y retículo endoplásmico (RE) dilatado. $23,54,55$ 
Los melanocitos en el vitíligo tienen mayor sensibilidad al estrés oxidativo debido a la reducción de la expresión de catalasa y glutatión peroxidasa, enzimas que se sabe metabolizan especies reactivas de oxígeno (ERO). ${ }^{56}$

Los melanocitos de pacientes con vitíligo han demostrado ser más difíciles de cultivar que los melanocitos de personas sin vitíligo, además, el proceso de melanogénesis es altamente costoso en energía, implica una importante hidroxilación y oxidación, durante el proceso se libera peróxido de hidrógeno, un precursor de especies reactivas de oxígeno. ${ }^{10,23,53,57-59}$

\section{ESPECIES REACTIVAS DE OXÍGENO}

Existen niveles elevados de ERO tanto en la piel lesionada como en la piel aparentemente sana..$^{20}$ El estrés oxidativo ocurre cuando la tasa de generación de ERO excede la capacidad de la célula para su eliminación. ${ }^{20}$ Los melanocitos no eliminan radicales libres de forma normal, lo que los hace susceptibles de generar estrés y daño de su membrana celular y membrana nuclear. ${ }^{51}$ Las ERO endógenas y exógenas incluyen el oxígeno «singlete» $\left({ }^{1} \mathrm{O}_{2}\right)$, anión superóxido $\left(\mathrm{O}_{2}^{-}\right)$, radicales hidroxilo $\left(\mathrm{OH}^{-}\right)$, peróxido de hidrógeno $\left(\mathrm{H}_{2} \mathrm{O}_{2}\right)$, anión de peroxinitrito (OONO-) y óxido nítrico (NO). ${ }^{50,60-62}$ Diversas vías metabólicas conducen a la generación incontrolada de ROS, las mitocondrias podrían ser la principal fuente de ERO en el vitíligo. ${ }^{20}$ Las ERO pueden crear un ambiente que contribuye a la producción de citocinas proinflamatorias y la activación del sistema inmunológico. ${ }^{20,53,57}$

\section{CAUSAS DEL AUMENTO DE ERO}

Hay varios motivos por los cuales el nivel de $\mathrm{H}_{2} \mathrm{O}_{2}$ puede elevarse en la piel con vitíligo tales como: aumento de las actividades de la óxido nítrico sintasa (ONS) y nicotinamida adenina dinucleótido fosfato oxidasa (NADPH), ${ }^{63}$ aumento en la monoamino oxidasa A (MAOA) que causa una acción citotóxica directa e indirecta al aumentar la producción de catecolaminas. ${ }^{64,65}$ Actividad de la oxidasa de neutrófilos y macrófagos, fotooxidación de la biopterina epidérmica- 6 , degradación de las bases de purina al ácido úrico por xantina oxidasa, actividad de la óxido nítrico sintasa (ONS) inducible por la epidermis. ${ }^{50}$

Se ha comunicado que ciertos elementos inducen a las células a generar ERO como el factor de necrosis tumoral alfa (TNF- $\alpha),{ }^{66}$ el factor de crecimiento fibroblástico básico (bFGF), además se incluye la participación de IL-6 e IL-1..$^{50}$

\section{CONSECUENCIAS DEL AUMENTO DE ERO EN LAS CÉLULAS}

El estrés oxidativo desempeña un papel esencial al activar las respuestas autoinmunes en vitíligo, la acumulación de ERO puede causar daño al ADN, oxidación de proteínas, fragmentación y peroxidación lipídica. ${ }^{20}$ Las ERO son reflejo de la pérdida de la homeostasis rédox de los melanocitos, por lo tanto, los melanocitos en situación de estrés generan patrones moleculares asociados al daño (PMAD) y autoantígenos, que en conjunto pueden activar la inmunidad innata y adaptativa, lo que lleva a la disfunción y muerte de los melanocitos a través de una cascada inflamatoria. ${ }^{67}$

La melanogénesis es una vía metabólica que requiere la síntesis de gran cantidad de proteínas para formar tirosinasa (TYR) y otras enzimas relacionadas. ${ }^{68}$ La tirosinasa es una enzima del melanocito que cataliza los pasos de la síntesis de melanina y es un autoantígeno importante reconocido por anticuerpos en pacientes con vitíligo . $^{69,70} \mathrm{El}$ aumento de los niveles de ERO modifica la TYR y otras proteínas melanogénicas. ${ }^{13} \mathrm{El} \mathrm{H}_{2} \mathrm{O}_{2}$ desactiva la dihidropteridina reductasa $y$, por lo tanto, da como resultado la modificación del sitio activo y favorece la síntesis y reciclaje de biopterina defectuosa, que en consecuencia interrumpen la síntesis de melanina. ${ }^{20}$ Un aumento en los niveles de tetrahidrobiopterina (6-BH4) conduce a la inhibición de la enzima fenilalanina hidroxilasa y provoca reducción en la síntesis de L-tirosina, que da como resultado deterioro en la producción de melanina. ${ }^{65}$

En las mitocondrias se produce alteración del potencial transmembrana mitocondrial y el complejo de la cadena respiratoria aumenta la malato deshidrogenasa mitocondrial con modificación de los componentes lipídicos de la membrana mitocondrial. ${ }^{67} \mathrm{La}$ sobreexpresión del miembro 2 de la subfamilia $\mathrm{M}$ del receptor de potencial transitorio de canal catiónico (TRPM2), impulsado por la participación de $\mathrm{H}_{2} \mathrm{O}_{2}$, aumenta el flujo de calcio mitocondrial y facilita la apoptosis de los melanocitos. ${ }^{71}$ En la piel de pacientes con vitíligo se han observado altas concentraciones de $\mathrm{H}_{2} \mathrm{O}_{2}$ a nivel epidérmico y un nivel reducido de catalasa. $\mathrm{El}_{2}^{2} \mathrm{O}_{2}$ desactiva la catalasa, la tiorredoxina reductasa (TRX) y la metionina sulfóxido reductasa. La desactivación mediada por $\mathrm{H}_{2} \mathrm{O}_{2}$ de la acetilcolinesterasa y butirilcolinesterasa induce altos niveles de acetilcolina en la epidermis de pacientes con vitíligo. ${ }^{23,50}$

El estrés oxidativo se extiende al RE, el cual se dilata en los melanocitos. EI RE es un sensor de estrés celular y el sitio de maduración de proteínas que requiere un 
entorno regulado para facilitar la formación de enlaces químicos necesarios para la estructura de la proteína secundaria y terciaria. La interrupción del balance redox y la interrupción de la maquinaria de plegado del RE resulta en la acumulación de proteínas mal plegadas, que a su vez activa la respuesta de proteínas no plegadas o mal plegadas (UPR)..$^{20,58,72,73}$

La UPR mejora el estrés del RE al disparar una interrupción transitoria en la síntesis de proteínas, aumenta la expresión de chaperonas que facilitan el plegamiento de proteínas y aumenta también la degradación de las proteínas mal plegadas. Si la célula no consigue este objetivo, la UPR dirige todo hacia la apoptosis. Puede activarse la degradación asociada a RE (DARE); sin embargo, la activación sostenida resulta en apoptosis. ${ }^{20,27,45}$ Los melanocitos pueden adaptarse a la actividad continua de UPR y evadir la muerte inducida. ${ }^{27}$ La UPR comprende tres ramas de señalización paralelas: la vía del factor de iniciación de la traducción eucariota (eiF2 $\alpha$ ), el factor de transcripción activador $6 \alpha$ (ATF6 $\alpha$ ) activado por estrés del retículo endoplásmico, la enzima-1 que requiere inositol (IRE1) y la proteína 1 de unión a la caja X (XBP1). ${ }^{20,39,74}$

La calreticulina (CRT), proteína del retículo endoplásmico que modula el calcio intracelular en la progresión de vitíligo ${ }^{45}$ se traslada a la superficie de los melanocitos desde la luz del retículo endoplásmico bajo estrés oxidativo. ${ }^{45,46}$

La CRT también induce la expresión de citocinas proinflamatorias como IL-6 y TNF- $\alpha$ que se correlaciona con las respuestas inmunitarias ${ }^{74}$ también ayuda en la presentación de antígenos y a romper la tolerancia inmunitaria. ${ }^{45}$ La sobreexpresión de la CRT de superficie aumenta la predisposición de los melanocitos a la apoptosis, esto último proporciona abundantes péptidos antigénicos a las células presentadoras de antígeno que conducen a la activación de las células T, promoviendo así la autoinmunidad. ${ }^{74}$ El desequilibrio redox de los lípidos de la membrana puede alterar su funcionalidad, lo que puede afectar la transducción intracelular mediada por receptores de membrana, transporte de electrones y energía mitocondrial. ${ }^{67}$

El aumento del estrés oxidativo y el defecto de adhesión están estrechamente vinculados. La peroxidación lipídica modifica la organización de los lípidos dentro de las membranas celulares. Los melanocitos de los pacientes con vitíligo tienen una expresión alterada de la E-cadherina. ${ }^{75}$ La E-cadherina es una molécula de adhesión dependiente de calcio que une los melanocitos a los queratinocitos circundantes. ${ }^{76}$ Un aumento en el estrés oxidativo disminuye la cantidad de E-cadherina en la membrana celular, debido a la activación de la cinasa Src, que desestabiliza el complejo E-cadherina/ $\beta$ catenina en la membrana por fosforilación, que induce su desprendimiento de la capa basal de la epidermis en condiciones de estrés. ${ }^{75,77-79}$ Las integrinas unen los melanocitos a la membrana basal. La exposición al estrés reduce aún más la expresión de E-cadherina, ésta es menor en comparación con los queratinocitos. La expresión reducida de E-cadherina interrumpe el contacto melanocito-queratinocito, desarraiga los melanocitos de su ubicación basal y éstos comienzan a moverse hacia arriba entre la epidermis. ${ }^{44,52}$ Ya que el estrés oxidativo afecta directamente la cantidad de Ecadherina en la membrana de los melanocitos, el estado de peroxidación de los lípidos de la membrana puede considerarse un marcador predictivo de la progresión de la despigmentación en pacientes con vitíligo. ${ }^{80} \mathrm{La}$ E-cadherina se encuentra distribuida de manera desordenada y reducida en los melanocitos obtenidos de la piel clínicamente normal de pacientes con vitíligo y se distribuye uniformemente entre la piel lesionada. ${ }^{44,52,75}$ No se han encontrado diferencias entre la piel con vitíligo y no lesional con respecto a los niveles de beta catenina y colágeno IV. ${ }^{81}$ Se ha demostrado que las tensiones mecánicas de rutina y la fricción provocan el desprendimiento de estos melanocitos con deficiencia de E-cadherina. ${ }^{52}$

El estrés oxidativo confiere un mecanismo explicable de cómo se inicia el vitíligo; sin embargo, no puede explicar todo del proceso de la enfermedad. ${ }^{67}$ Los queratinocitos con bajas concentraciones de catalasa favorecen el estrés oxidativo, puesto que la catalasa es la enzima principal implicada en la eliminación de $\mathrm{H}_{2} \mathrm{O}_{2}$, su disminución propicia la aparición de estrés biológico. ${ }^{65,82}$

La frecuencia elevada de células Th17, junto con un nivel más alto de IL-17, está fuertemente correlacionada con la actividad, la extensión y gravedad. Su actividad influye en la producción de TNF- $\alpha$, que también está elevado en el vitíligo. ${ }^{9,67,83-86}$ La IL-17 aumenta los efectos de TNF- $\alpha$, IL-1 $\beta$ o IL-6 para inhibir la función y supervivencia de los melanocitos. ${ }^{87} \mathrm{Al}$ liberar IL-17, las células Th17 pueden inducir la secreción de citocinas proinflamatorias, que a su vez reclutan y activan linfocitos mononucleares fuertemente involucrados en la progresión de la enfermedad. ${ }^{83}$

\section{DEFENSA CONTRA EL ESTRÉS OXIDATIVO}

La eliminación de daños o la reparación de enzimas ayudan en la regeneración de biomoléculas y la recu- 
peración del daño oxidativo. ${ }^{67}$ La homeostasis celular en la piel está dada por mecanismos de defensa, estas defensas incluyen enzimas tales como superóxido dismutasa, ${ }^{8,33}$ catalasa, ${ }^{8}$ glutatión reductasa (GR), glutatión peroxidasa (GP), glutatión-S-transferasa (GST), tiorredoxina reductasa (TRX), tiorredoxina peroxidasa (TPX) y metionina sulfóxido reductasa A (MetSO A) y $\mathrm{B}$ (MetSO B) ${ }^{50}$ Se incluyen antioxidantes moleculares pequeños como la vitamina $C$ (ácido ascórbico), vitamina $E$ (alfa-tocoferol), glutatión, ácido lipoico, algunos aminoácidos (metionina y triptófano), el selenio y las tetrahidrobiopterinas 6 y 7.50,67 También se incluyen los betacarotenos, la ubiquinona, la ferritina, la metalotioneína, ${ }^{45}$ el polypodium leucotomos y el Ginkgo biloba. ${ }^{88}$ Los antioxidantes administrados por vía tópica o sistémica teóricamente serían prometedores, aunque los resultados son variables. ${ }^{89-92}$

Aparte de la función antioxidante enzimática y no enzimática, existen otras vías que pueden proteger a los melanocitos del daño oxidativo como la vía del factor nuclear eritroide 2 (Nrf2), elemento de respuesta antioxidante (ARE), hemoxigenasa 1 (HO-1) denominada vía Nrf2/ARE/HO-1. ${ }^{45,67,93,94}$ El factor de transcripción Nrf2 está involucrado en la activación de UPR, regula los genes que contienen los elementos de respuesta antioxidante en sus promotores y proteínas codificantes que protegen contra el daño oxidativo provocado por lesiones e inflamación. ${ }^{20,95}$ Se ha demostrado que la vía Nrf2/ARE/HO-1 es funcionalmente deficiente en la epidermis de pacientes con vitíligo. ${ }^{96}$ Esto es importante para el mantenimiento del estado redox dentro de las células, ya que podrían ayudar a reducir el daño a la E-cadherina que es sostenido por el estrés lipoperoxidativo. ${ }^{75}$ En la Figura 1 se resume la participación de los factores endógenos y exógenos en la patogenia del vitíligo.

\section{PARTICIPACIÓN DEL SISTEMA INMUNOLÓGICO EN EL VITÍLIGO}

\section{Inmunidad innata}

Las células NK y CD representan la inmunidad innata. La inmunidad innata es el enlace entre el estrés oxidativo y los receptores de reconocimiento de patrones (PRR); cuando los ligandos PRR se derivan de patógenos virales y bacterianos, se les conoce como patrones moleculares asociados con patógenos (PMAP). ${ }^{23,58}$ En el vitíligo el sistema inmunológico innato se activa sin un reconocimiento específico de antígeno, lo logra a través de los PRR por «señales de peligro». 20,23,58
En el vitíligo ocurre algo denominado «inflamación estéril», los melanocitos en respuesta al estrés liberan PMAD, activando los PRR para iniciar la inflamación. ${ }^{58}$ Los PMAD no están relacionados con los patrones moleculares asociados con patógenos (PMAP) ${ }^{97}$ Los PMAD en vitíligo proporcionan la señal de peligro y actúan como ligando para los receptores de reconocimiento de patrones innatos (receptores de peaje y receptores de oligomerización de nucleótidos), los PMAD pueden ser secretados por las células, liberados durante el daño celular o su muerte o pueden ser transportados por exosomas. ${ }^{58}$ En el vitíligo la monobenzona aumenta la secreción de exosomas por los melanocitos, ${ }^{58,98}$ los exosomas son microvesículas secretadas por las células como un medio de comunicación de célula a célula. ${ }^{58}$ La secreción de exosomas proporciona un medio por el cual los melanocitos comunican el estrés al sistema inmunológico innato. ${ }^{58}$

Los PMAD secretados por exosomas pueden ser miARN y principalmente proteínas de choque térmico (HSP70). El miARN miR-29b es inducido por estrés oxidativo y los exosomas que contienen miR-29b inducen la activación de macrófagos, los exosomas liberan antígenos diana del vitíligo que son reconocidos por las $C D$, contribuyen a su activación y conducen a la inducción de respuestas de células T autoinmunes contra los melanocitos y los melanosomas. ${ }^{98}$

HSP70 es una familia de proteínas que incluye HSP70 constitutivo y HSP70 inducible (HSP70i), HSP70i acelera la progresión de la enfermedad. ${ }^{67,99-103} \mathrm{La}$ HSP70 activa y propicia la migración de células asesinas naturales (NK) al producir señales inflamatorias y proinflamatorias, ${ }^{58}$ induce células dendríticas inflamatorias, las células dendríticas elevan la expresión del ligando inductor de apoptosis relacionado con el receptor de factor de necrosis tumoral (TRAIL), y los receptores HSP70i en su superficie. ${ }^{67,104,105}$

CD91 inducido por HSP70i, ayuda a explicar los mecanismos moleculares que HSP70i utiliza para activar las células dendríticas. ${ }^{67,106} \mathrm{Hsp} 70 \mathrm{i}$ al interactuar con el ADN mitocondrial y en conjunto con HMGB1 y CRT, HSP70i aceleran la progresión de la enfermedad, ${ }^{99,100,103}$ HMGB1 actúa como una alarma y puede interactuar con múltiples sensores y receptores inmunes como productos finales de glicación avanzada (RAGE) así como TLR2, TLR4 y TLR9 que conduce a la activación de NF-кB y a la producción de IL-6 y TNF- $\alpha .{ }^{60}$

Retomando a los PRR, éstos se dividen en dos subgrupos según su distribución: endosómicos o citosólicos. ${ }^{20}$ Estos receptores están originalmente es- 


\section{Patogénesis del vitíligo}

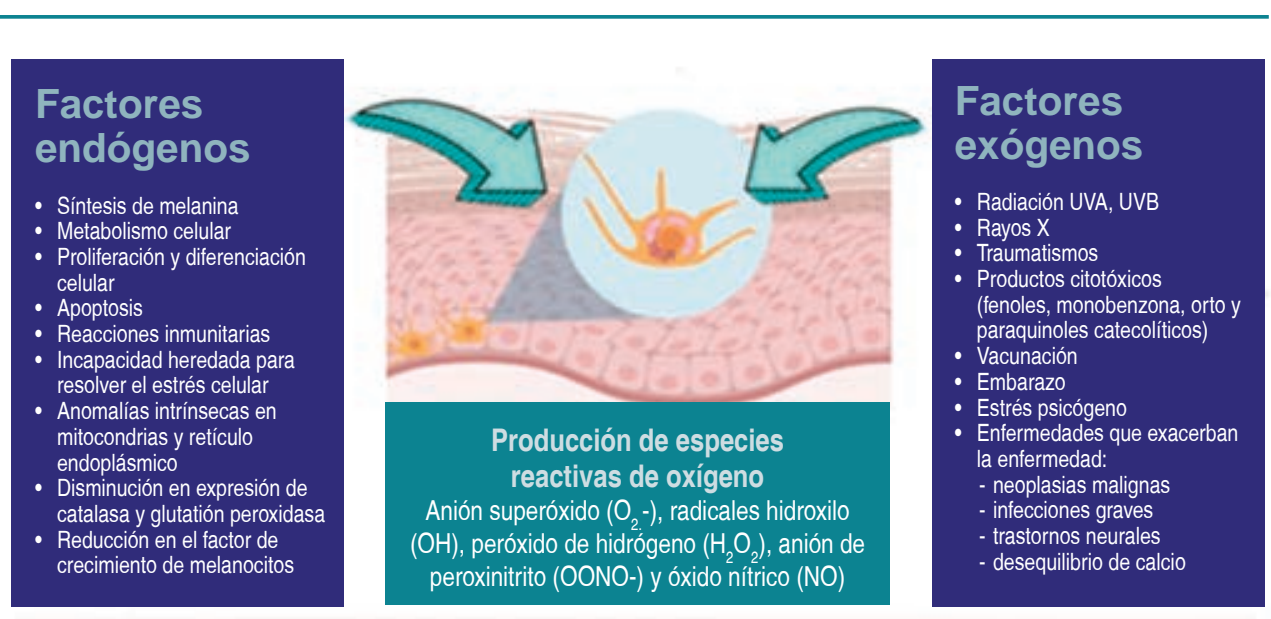

Figura 1:

Factores endógenos, exógenos y consecuencia del aumento de especies reactivas de oxígeno.

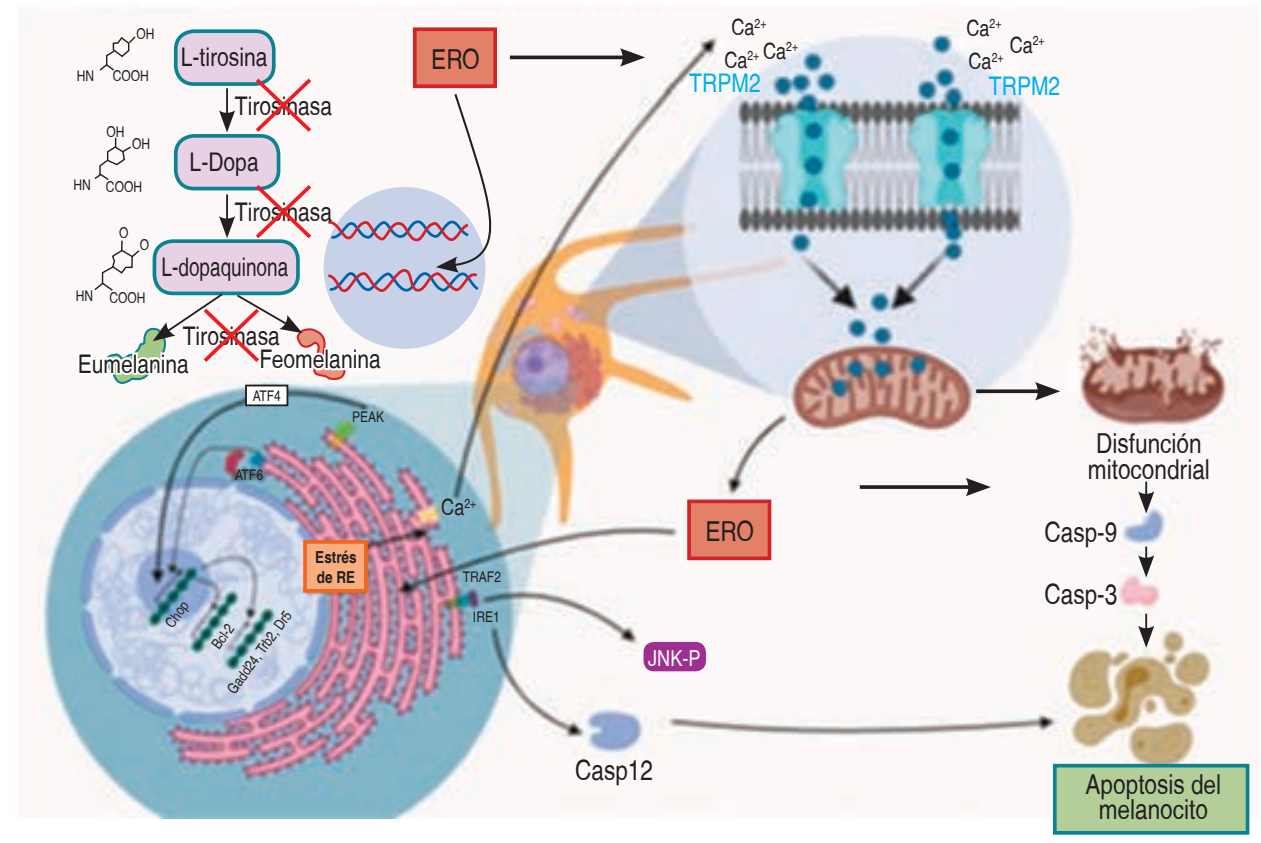

pecializados en la detección de patógenos a través de patrones moleculares asociados a patógenos (PAMP)..$^{20}$ En los endosomas, estos receptores incluyen receptores tipo Toll (TLR) como TLR3, TLR7, TLR8 y TLR9. TLR3 reconoce el ARN de cadena doble (ds), TLR7 y TLR8 reconocen el ARN de cadena sencilla (ss), TLR9 detecta la presencia de ADN que contiene CpG, lo que lleva a la transcripción de citocinas proinflamatorias como el TNF- $\alpha$, IL-6 e interferón tipo I (IFN) $\alpha / \beta$. Dentro del grupo de receptores endosómicos en células dendríticas y melanocitos se encuentran también los receptores similares a dominios de oligomerización de nucleótidos (NOD) (NLR) y receptores tipo RIG-I (RLR). ${ }^{20,60,107}$
En el citosol, los receptores de ácido nucleico abarcan los receptores similares al gen I (RIG-I) inducible por ácido retinoico, los sensores y receptores de ADN citosólico están involucrados en la formación del inflamasoma. ${ }^{108-110}$ Los receptores citosólicos reclutan la proteína adaptadora ASC para formar un complejo de inflamasoma que activa la caspasa 1, lo que lleva al procesamiento y la liberación de IL-1 $\beta$ e IL-18. ${ }^{111,112}$

Se han descrito varios inflamasomas que son definidos por las proteínas receptoras de tipo NOD que contienen: el inflamasoma NLRP1 (NALP1), el inflamasoma LRP3 (NALP3) y el inflamasoma IPAF (NLRC4). ${ }^{113}$ La expresión de NLRP1 e IL-1 $\beta$ en la piel 
perilesional de vitíligo se asocia con la progresión de la enfermedad. ${ }^{114}$

Las respuestas inmunitarias antes mencionadas activan las células dendríticas que transportan y presentan antígenos específicos de los melanocitos a las células T en los tejidos linfoides. ${ }^{23,49,54}$

Las citocinas secretadas son la señal inicial para ayudar a las células $T$ a localizar los melanocitos estresados, ya que los melanocitos de la epidermis están alejados de los vasos sanguíneos, las quimiocinas actúan como quimioatrayentes para guiar la migración de las células $T$, promueven el reclutamiento de células T CD8 circulantes en el tejido periférico. ${ }^{23} \mathrm{HSP} 70 \mathrm{i}$ potencia la generación de IFN- $\alpha$ por un subconjunto de células dendríticas y posteriormente, la expresión de CXCL9 y CXCL10 por los queratinocitos, conocida de manera importante por el reclutamiento de células $T$ CXCR3+CD8+ o como cascada inflamatoria de HSP70ipDCs-IFN- $\alpha-C X C L 9$ y CXCL10-CTL. Las quimiocinas CXCL9, 10 y 11 inducidas por IFN- $\gamma$ son altamente expresadas en la piel y sangre. ${ }^{33,42,106,115}$ CXCL10 se requiere para la progresión y mantenimiento de la enfermedad, por lo que se sugiere como biomarcador para monitorear la actividad de la enfermedad y la respuesta al tratamiento. ${ }^{42}$

\section{INMUNIDAD ADAPTATIVA}

La inmunidad celular en el vitíligo tiene una mayor participación, mientras que la inmunidad humoral probablemente tiene un papel secundario. ${ }^{116}$ En las áreas de vitíligo perilesional, el receptor conocido como el ligando de la apoptosis relacionado con TNF (TRAIL) y CD se observa cerca de los melanocitos que expresan el receptor TRAIL. Los melanocitos sólo expresan una pequeña cantidad de TRAIL-R2 en su superficie y cantidades marginales de TRAIL-R1 y R3. ${ }^{117,118}$

Los melanocitos muertos se convierten en una fuente de antígenos para su procesamiento por las CD y su presentación a las células $\mathrm{T}$. En las lesiones tempranas de vitíligo se encuentran células T CD4 y CD8 acompañadas de macrófagos para eliminar residuos celulares y ayudar en la restauración de tejidos. ${ }^{117}$ Los macrófagos y las células dendríticas inducen respuestas de células Treg y Th17, respectivamente. HSP70i mediante la activación de células dendríticas puede regular la inhibición de la actividad de macrófagos de las Treg y apoyar la autoinmunidad mediada por Th17. ${ }^{67,119}$

El vitíligo en humanos y ratones refleja en la piel una respuesta relacionada con la vía T-helper 1 (Th1) específica de IFN- $\gamma$ y las citocinas dependientes de
IFN- $\gamma .{ }^{120-125}$ La proporción de células CD4+/CD8+ aumenta en la sangre periférica con predominio de células CD8 en la sangre de pacientes con vitíligo. ${ }^{23,126}$ Las células T CD8+ citotóxicas, específicas para los melanocitos, han estado muy implicadas en su destrucción. ${ }^{23,127}$ Se han detectado células T CD8 específicas para antígenos de melanocitos, el antígeno de melanoma reconocido por las células T (MelanA/MART-1), tirosinasa 1 y 2 y la glucoproteína 100 (gp100).67,116,127-134

Los anticuerpos contra los melanocitos humanos normales se han detectado con ensayos de inmunoprecipitación específicos, ${ }^{135,136}$ y tienen un efecto citolítico en los melanocitos. ${ }^{137}$ La presencia de estos anticuerpos contra melanocitos se ha relacionado con la actividad de la enfermedad. ${ }^{138}$ No está claro si estos anticuerpos participan en el inicio de la enfermedad o son un resultado secundario. ${ }^{116}$

Otra observación importante es la expresión del antígeno de linfocitos cutáneos (CLA) por las células CD8+, un receptor de referencia en la piel que podría reclutar células $\mathrm{T}$ desde la circulación hasta la piel afectada. ${ }^{67,131,139}$ En la piel perilesional de vitíligo inflamatorio en la unión dermoepidérmica se encuentran linfocitos CD4+ y CD8+, ,34 expresan la granzima B y producen citocinas relacionadas con Tc1 como IFN- $\gamma$, TNF- $\alpha$ e IL-17. ${ }^{135-138}$ Se ha observado que IFN- $\alpha$ inhibe directamente la melanogénesis (inhibición funcional o cualitativa) y da como resultado la apoptosis de los melanocitos (inhibición cuantitativa). ${ }^{140}$ Induce la senescencia de los melanocitos y promueve la liberación de la proteína de choque térmico HSP70, que marca el daño de los melanocitos por la respuesta inmunitaria innata. ${ }^{141}$

Estudios in vivo realizados en modelos de ratón similares mostraron que la despigmentación en ratones depende de IFN- $\gamma$, mientras que los mediadores citotóxicos como la perforina o la granzima eran prescindibles. ${ }^{122,142,143} \mathrm{EI}$ IFN- $\gamma$ y las quimiocinas inducidas (CXCL9 y CXCL10) se expresan en gran medida en la piel y la sangre de pacientes con vitíligo. ${ }^{23}$ Además, IFN- $\gamma$ y CXCL10 se requieren tanto para la progresión como para el mantenimiento de la enfermedad. ${ }^{23,144}$

La CXCL10 sérica es mayor en pacientes con vitíligo en comparación con los controles sanos, su nivel se encuentra asociado con actividad de la enfermedad y disminuye significativamente después de un tratamiento exitoso, por lo cual se podría utilizar como biomarcador para monitorear la actividad de la enfermedad y la respuesta al tratamiento. ${ }^{23}$ La CXCL10 impulsa el reclutamiento de células T CD8 al interactuar con el receptor CXCR3, que se expresa en las células T auto- 
rreactivas tanto en la sangre como en la piel lesional. El eje IFN- $\gamma$-CXCL10-CXCR3 es considerado por algunos autores como el controlador clave de la autoinmunidad en el vitíligo. Se monitoreó el IFN- $\gamma$ y se observó que fue producido principalmente por CTL, por lo que el eje IFN- $\gamma$-CXCL10-CXCR3 se transforma en un circuito de retroalimentación positiva. ${ }^{122,124,142,145-147}$

El INF- $\gamma$ causa directamente apoptosis de melanocitos y favorece la entrada de células T activadas en la piel a través de quimiocinas liberadas también por los queratinocitos. ${ }^{147}$

\section{PARTICIPACIÓN DE LOS QUERATINOCITOS}

El daño a los queratinocitos puede generar apoptosis de melanocitos, este daño a los queratinocitos produce niveles bajos de citocinas que estimulan los melanocitos, como el factor de células madre (SCF) y la endotelina 1 (ET-1), también produce altos niveles de citocinas que inhiben los melanocitos, como el TNF- $\alpha$ y la IL-6, esto causa una apoptosis posterior o muerte de melanocitos. Por lo tanto, el envejecimiento acelerado de los queratinocitos en el vitíligo puede estar involucrado en su patogénesis..$^{50}$ Los queratinocitos del vitíligo podrían tener una participación importante a través de la liberación de ligandos de quimiocinas fundamentales para el reclutamiento de células $T$. La activación de la respuesta de proteínas mal plegadas (UPR) en queratinocitos indujo la producción de CXCL16, CXCL9, CXCL10, lo que llevó al reclutamiento de linfocitos T CD8 CXCR6 ${ }^{+}$ y se demostró que iniciaron respuesta inmunitaria adaptativa, ${ }^{20,148}$ esto era distinto de los estímulos de citocinas tradicionales como TNF- $\alpha$, interferón gamma (IFN- $\gamma$ ) e IL-1 $\beta$, conocida por inducir la producción de citocinas, también puede actuar como un inductor de células Th17. ${ }^{114}$

La vía Th1 se considera bastante significativa en el vitíligo, y se cree que estas células $T$ producen cantidades elevadas de IFN- $\gamma$. En la cascada de señalización de IFN- $\gamma$ son importantes las cinasas Janus (JAK) y los transductores de señal y activadores de la transcripción (STAT). Las JAK ubicadas dentro de los queratinocitos se activan una vez que el IFN- $\gamma$ se une a su receptor en un queratinocito, ${ }^{67,149}$ su activación es seguida de la translocación de STAT1 al núcleo, donde activa la transcripción de genes sensibles a IFN- $\gamma$ tempranos e intermedios que incluyen CXCL9 y 10. CXCL9 y 10 son quimiocinas que actúan sobre el receptor CXCR3 presente en las células $\mathrm{T}$ y resultan en un mayor reclutamiento de células T citotóxicas en la piel con vitíligo. ${ }^{115,150}$

\section{CÉLULAS T DE MEMORIA RESIDENTES}

La piel humana contiene cerca de 20,000 millones de células $T$, la mayoría de ellas son células $T$ residentes de memoria $\left(T_{R M}\right) \cdot{ }^{156}$ Las $T_{R M}$ en la piel emergen de precursores de células $T$ que carecen del marcador de células efectoras KLRG1, la TRM reside en tejidos de barrera epitelial, en la interfaz entre el entorno y el hospedero, no circulan en la sangre periférica y actúan independientemente del reclutamiento de células $T$ desde la circulación; ${ }^{151}$ asimismo, proliferan localmente, pueden estimularse de manera repetida y proporcionan una defensa inmunitaria rápida en el sitio donde se encuentran, este enfoque puede ayudar a explicar la recurrencia de una lesión de vitíligo en la misma ubicación. Por lo regular, las células $\mathrm{T}_{\mathrm{RM}}$ proporcionan una rápida defensa localizada contra patógenos invasores y recurrentes, responden rápidamente a los antígenos o patógenos extraños que intentan romper el epitelio de la piel, lo que lleva a una inmunidad protectora. ${ }^{67,152,153}$ En las células $\mathrm{T}_{\mathrm{RM}}$ se ha identificado un fenotipo de memoria con un programa transcripcional distinto, expresan marcadores de superficie celular, se ha identificado como fenotipo CD122 (receptor de IL-15), CD103, CD69, CD49a y CD44, aunque se requieren más estudios de laboratorio para demostrar sus funciones interactuando con otras células y citocinas, ${ }^{67}$ están involucradas en la regulación descendente de la expresión en la superficie del receptor 1 de la esfingosina fosfato 1 (S1PR1) requerido para la salida de células $T$ de los tejidos, ${ }^{67}$ muestran un fenotipo de memoria efectora y expresan altos niveles de receptores de localización a piel como CLA y el receptor de quimiocinas CCR4,CD69, CD103.151

Las $T_{R M}$ se acumulan tanto en la epidermis como en la dermis de la piel perilesional de pacientes con vitíligo, las $T_{R M}$ específicas de melanocitos se caracterizan por la expresión de bajos niveles de CXCR3 y altos niveles de citocinas proinflamatorias TNF- $\alpha$ e IFN- $\gamma$, las células $\mathrm{T}_{\mathrm{RM}}$ específicas contra melanocitos están presentes en el vitíligo. ${ }^{151} \mathrm{La}$ acumulación de $\mathrm{T}_{\mathrm{RM}}$ en la piel perilesional de pacientes con enfermedad estable enfatiza su participación durante la reactivación de la enfermedad, esto podría ocurrir durante los brotes repetitivos de la enfermedad, lo que lleva al reclutamiento de nuevas poblaciones de $\mathrm{T}_{\mathrm{RM}}$ en piel, no sólo en el lugar del brote, sino en el resto del cuerpo. La función de las células $\mathrm{T}_{\mathrm{RM}}$ se basa en la captación de lípidos exógenos y el metabolismo oxidativo, existe un vínculo entre el estrés oxidativo y la inmunidad adaptativa de memoria. ${ }^{67}$ Las $T_{R M}$ liberan citocinas inflamatorias, son estimuladas por IL-15 y están preparadas para la respuesta citotóxica 
con la expresión de moléculas efectoras como perforina y granzima $B .54,67$

Las células $T_{R M}$ y las células $T$ recirculantes de memoria $\left(T_{C M}\right)$ colaboran para mantener las lesiones, entendiendo así al vitíligo como una enfermedad que se relaciona con la memoria de la piel. ${ }^{67}$ Se encuentran células T CD8+ de memoria residente tanto en el vitíligo activo como en el vitíligo estable, lo que podría conducir a recaídas. ${ }^{154}$ Las $T_{R M}$ pueden tener la función alterada y generar una respuesta autorreactiva local. La activación inadvertida de estos $T_{\mathrm{RM}}$ debe controlarse estrechamente, una población residente de células $T$ reguladoras puede proliferar localmente y amortiguar la respuesta de $T_{R M}$ de la piel, existe así pérdida de «autotolerancia» en la piel de vitíligo. ${ }^{155-157}$ La inhibición de las células $T$ reguladoras $\left(T_{R E G}\right)$ por $T_{R M}$ y citocinas proinflamatorias producidas (como IFN- $\gamma$ y TNF- $\alpha$ ) podrían tener un efecto indirecto en la inhibición de la regeneración de melanocitos.

\section{CÉLULAS T REGULADORAS}

Las células $T$ reguladoras $\left(T_{R E G}\right)$ pueden proliferar localmente y amortiguar las respuestas de las células $\mathrm{T}$ de memoria efectoras de la piel, se encargan de la supresión de las células T autorreactivas. ${ }^{158}$ Las células $T_{\text {REG }}$ suprimen las células T CD8+, hacen que las células TCD8 sean hipoproliferativas e hipoproductoras de citocinas. ${ }^{159}$ Cuando las células T CD8+ no son inhibidas pueden contribuir a una despigmentación duradera. ${ }^{26}$ En pacientes con vitíligo las células $T_{\text {REG }}$ se encuentran disminuidas en número y tienen funcionamiento defectuoso, lo que aumenta el daño contra los melanocitos, en pacientes con vitíligo hay alteraciones en la función de células $T_{R E G}$. Dentro de las alteraciones presentes se encuentra menor expresión del factor de crecimiento transformante beta (TGF- $\beta$ ) y disminución significativa en la expresión de FOXP3. El factor de transcripción FOXP3 puede regular negativamente la activación de las células $T$ y los genes de las citocinas (p. ej. IL-2, IL-4); regula también las moléculas inmunosupresoras de la superficie de las células (p. ej. CD25, CTLA-4). Existe disminución en el receptor homing CCL22 en la piel del vitíligo, la sobreexpresión de CCL22 restablece la población de $\mathrm{T}_{\mathrm{REG}}$ residente y puede suprimir la actividad del vitíligo. ${ }^{119,129,160}$

\section{VITÍLIGO Y OTRAS ENFERMEDADES}

Los pacientes con vitíligo y sus familiares tienen mayor riesgo de desarrollar otras enfermedades autoinmu- nes. ${ }^{23}$ La teoría autoinmune sugiere que los melanocitos son destruidos por un mecanismo autoinmune. La correlación entre vitíligo y autoinmunidad se centra en:

1. Prevalencia de los mismos trastornos autoinmunes en familiares de primer grado no afectados de pacientes con vitíligo así como afectación en los ojos y el oído interno. ${ }^{21,161,162}$

2. Alta prevalencia de autoanticuerpos contra los melanocitos en pacientes con vitíligo. ${ }^{151}$

3. La presencia frecuente de trastornos autoinmunes concomitantes se observa en $10-15 \%$ de los pacientes con vitíligo en comparación con 1-2\% de la población general. ${ }^{151}$ En el Centro Dermatológico «Dr. Ladislao de la Pascua» se encontraron trastornos autoinmunes en pacientes con vitíligo segmentario en $0.7 \%$, en vitíligo generalizado en $0.11 \%$ y vitíligo universal en $6.2 \%$.

4. Linfocitos infiltrantes en el margen de las lesiones de vitíligo, CTL circulantes específicos de melanocitos en pacientes con vitíligo. ${ }^{131,163,164}$

El vitíligo puede estar asociado con varias enfermedades autoinmunes como enfermedades autoinmunes de tiroides, alopecia areata, halo nevus, enfermedad de Addison, lupus eritematoso sistémico (LES), artritis reumatoide, dermatomiositis, esclerodermia, psoriasis, anemia perniciosa y enfermedades inflamatorias del intestino (evento poco frecuente). ${ }^{42,165-167,172}$ Las enfermedades autoinmunes afectan hasta $20 \%$ de los pacientes caucásicos. ${ }^{168,169}$ La tiroiditis de Hashimoto es de los trastornos más comunes asociados con el vitíligo. ${ }^{169,170}$ El vitíligo puede estar presente en todos los síndromes poliglandulares autoinmunes (APS). ${ }^{171}$ Las mujeres tienen más probabilidades de tener enfermedad de Graves, tiroiditis de Hashimoto, dermatitis atópica, artritis reumatoide, LES y síndrome de Sjögren, mientras que los hombres tienen más probabilidades de tener psoriasis. Además, el LES y el síndrome de Sjögren son más frecuentes en pacientes de edad avanzada, mientras que la miastenia gravis es más frecuente en pacientes jóvenes con vitíligo. ${ }^{166}$ Aunque todavía no se conoce bien el papel de los anticuerpos antimelanocitos en el vitíligo, se han encontrado altos niveles de autoanticuerpos circulantes en aproximadamente 10\% de los pacientes, especialmente contra la tirosinasa 1 y 2 (TRP-1 y TRP-2). ${ }^{172-175}$ Su detección podría estar relacionada con el daño de los queratinocitos y melanocitos. ${ }^{32}$ Se ha comunicado el desarrollo de vitíligo en receptores de trasplante de médula ósea de donantes que tienen vitíligo. ${ }^{49,176,177}$ Molecularmente en el vitíligo 


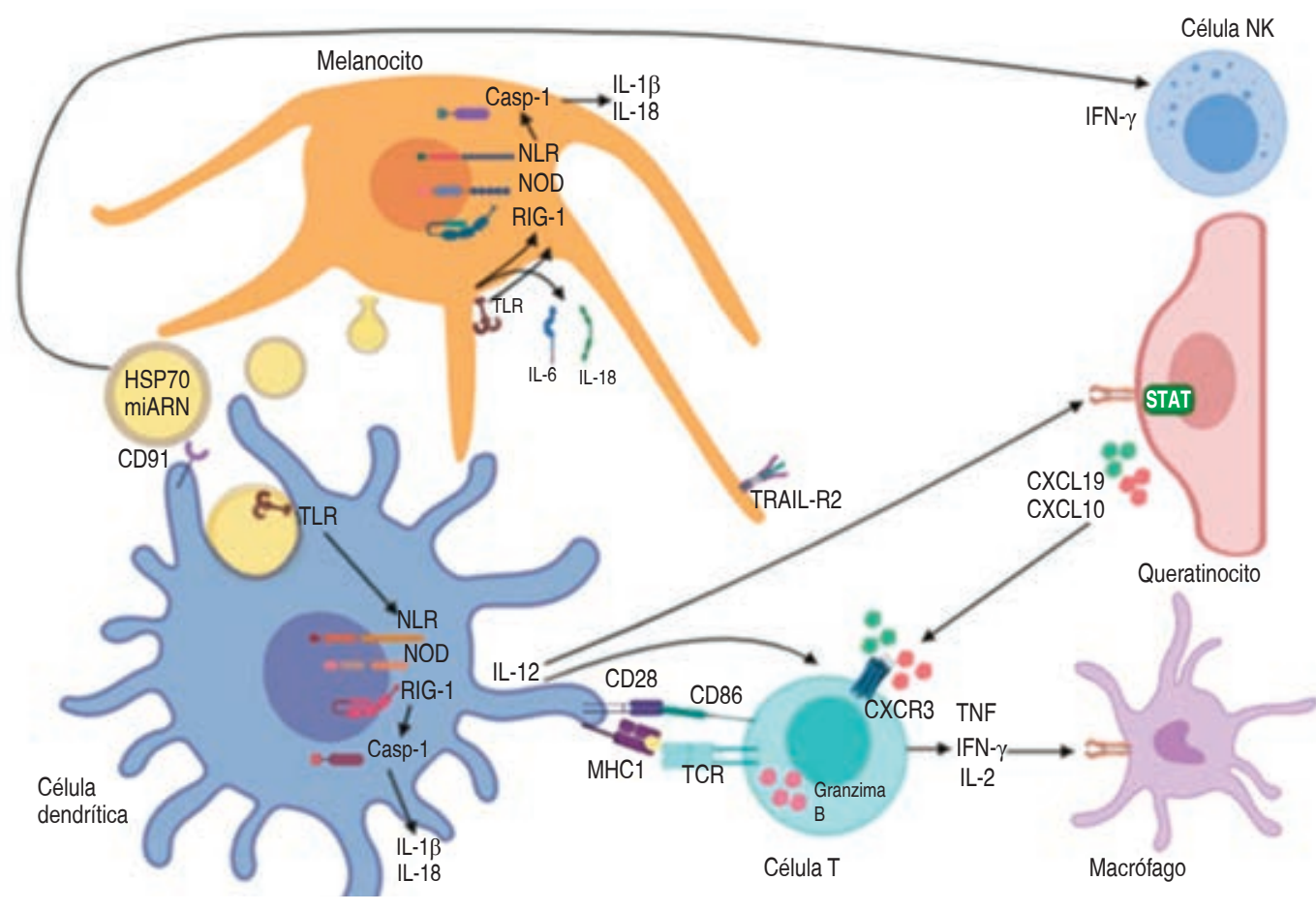

Figura 2:

Inmunidad innata y adaptativa en la patogénesis del vitíligo. se ha demostrado que el interferón gamma (IFN- $\gamma$ ) es un mediador importante en las acciones de los linfocitos $T$ citotóxicos, similar al liquen plano y al LES. ${ }^{54}$ La primera evidencia directa de respuestas de células T citotóxicas que causan despigmentación de la piel provino de pacientes con melanoma, donde la mayoría de las células $T$ que infiltran tumores de melanoma son reactivas a MelanA y gp100. ${ }^{178,179}$ Esta desregulación conduce a una capacidad disminuida para amortiguar los procesos inflamatorios activos y, por lo tanto, un umbral reducido para desarrollar trastornos autoinmunes. ${ }^{180}$ En la Figura 2 se esquematiza la interacción patogénica de la inmunidad innata y adaptativa en el vitíligo.

\section{CONCLUSIONES}

Es notoria la incidencia del vitíligo en México, una enfermedad con patogenia muy compleja que afecta de manera significativa la calidad de vida de quienes la padecen. Se han propuesto diferentes hipótesis para explicar el origen de esta enfermedad, aun así, sigue siendo de gran utilidad conceptualizar al vitíligo como una enfermedad autoinmune. Esta teoría es respaldada por los anticuerpos presentes en la piel de los pacientes con esta enfermedad y trastornos autoinmunes agregados. Los estudios recientes han enriquecido los detalles de cómo la respuesta oxidativa permite la activación del sistema inmunológico, lo que abre interesantes perspectivas para innovar estrategias de tratamiento.

No podemos atribuir la patogénesis de esta enfermedad sólo a un deterioro inmunológico, cuando es evidente que existen diferentes factores en la consolidación de esta enfermedad. Investigaciones posteriores podrían centrarse en relacionar a mayor profundidad la participación del fenómeno de Koebner y la alteración presente en E-cadherina así como en el nuevo enfoque que se tiene con la participación de los queratinocitos, lo que podría llevar al desarrollo de terapias blanco en contra de los factores endógenos en los melanocitos. Es relativamente común en estos pacientes encontrar familiares de primer grado con vitíligo, demostrando que el factor genético es fundamental en el desarrollo de esta enfermedad.

\section{REFERENCIAS}

1. Rodríguez-Cerdeira C, Arenas GR. El vitíligo, una enfermedad estigmática: un recorrido a través de su historia. Med Cutan Iber Lat Am. 2011; 39: 278-282.

2. Gawkrodger DJ, Ormerod AD, Shaw L, Mauri-Sole I, Whitton ME, Watts MJ et al. Guideline for the diagnosis and management of vitiligo. Br J Dermatol. 2008; 159: 1051-1076.

3. Ezzedine K, Eleftheriadou V, Whitton M, van Geel N. Vitiligo. Lancet. 2015; 386: 74-84. 
4. Picardo M, Dell'Anna ML, Ezzedine K, Hamzavi I, Harris JE, Parsad D, Taieb A. Vitiligo. Nat Rev Dis Primers. 2015; 1: 15011.

5. Taieb A. Vitiligo as an inflammatory skin disorder: a therapeutic perspective. Pigment Cell Melanoma Res. 2012; 25: 9-13.

6. Ezzedine K, Lim HW, Suzuki T, Katayama I, Hamzavi I, Lan CC et al. Revised classification/nomenclature of vitiligo and related issues: the Vitiligo Global Issues Consensus Conference. Pigment Cell Melanoma Res. 2012; 25: E1-13.

7. Goding CR. Melanocytes: the new black. Int J Biochem Cell Biol.2007; 39: 275-279.

8. Bassiouny DA, Shaker O. Role of interleukin-17 in the pathogenesis of vitiligo. Clin Exp Dermatol. 2011; 36: 292-297.

9. Khan R, Satyam A, Gupta S, Sharma VK, Sharma A. Circulatory levels of antioxidants and lipid peroxidation in Indian patients with generalized and localized vitiligo. Arch Dermatol Res. 2009; 301: 731-737.

10. Schallreuter KU, Moore J, Wood JM, Beazley WD, Gaze DC, Tobin DJ et al. In vivo and in vitro evidence for hydrogen peroxide (H2O2) accumulation in the epidermis of patients with vitiligo and its successful removal by a UVB-activated pseudocatalase. J Investig Dermatol Symp Proc. 1999; 4: 91-96.

11. Dammak I, Boudaya S, Ben Abdallah F, Turki H, Attia H, Hentati B. Antioxidant enzymes and lipid peroxidation at the tissue level in patients with stable and active vitiligo. Int J Dermatol. 2009; 48: 476-480.

12. Sravani PV, Babu NK, Gopal KV, Rao GR, Rao AR, Moorthy B et al. Determination of oxidative stress in vitiligo by measuring superoxide dismutase and catalase levels in vitiliginous and non-vitiliginous skin. Indian J Dermatol Venereol Leprol. 2009; 75: 268-271.

13. Rodrigues M, Ezzedine K, Hamzavi I, Pandya AG, Harris JE; Vitiligo Working Group. New discoveries in the pathogenesis and classification of vitiligo. J Am Acad Dermatol. 2017; 77: 1-13. Available from: http://dx.doi.org/10.1016/j.jaad.2016.10.048

14. Le Poole IC, van den Wijngaard RM, Westerhof W, Das PK. Tenascin is overexpressed in vitiligo lesional skin and inhibits melanocyte adhesion. Br J Dermatol. 1997; 137: 171-178.

15. Gauthier Y, Cario-Andre M, Lepreux S, Pain C, Taieb A. Melanocyte detachment after skin friction in non lesional skin of patients with generalized vitiligo. Br J Dermatol. 2003; 148: 95-101.

16. Gauthier $Y$, Cario Andre M, Taieb A. A critical appraisal of vitiligo etiologic theories. Is melanocyte loss a melanocytorrhagy? Pigment Cell Res. 2003; 16: 322-332.

17. Kroll TM, Bommiasamy H, Boissy RE, Hernandez C, Nickoloff BJ, Mestril $R$ et al. 4-Tertiary butyl phenol exposure sensitizes human melanocytes to dendritic cell-mediated killing: relevance to vitiligo. $J$ Invest Dermatol. 2005; 124: 798-806.

18. Ricard AS, Pain C, Daubos A, Ezzedine K, Lamrissi-Garcia I, Bibeyran A et al. Study of CCN3 (NOV) and DDR1 in normal melanocytes and vitiligo skin. Exp Dermatol. 2012; 21: 411-416.

19. Cario-André M, Pain C, Gauthier Y, Taieb A. The melanocytorrhagic hypothesis of vitiligo tested on pigmented, stressed, reconstructed epidermis. Pigment Cell Res. 2007; 20: 385-393.

20. Boniface K, Seneschal J, Picardo M, Taieb A. Vitiligo: focus on clinical aspects, immunopathogenesis, and therapy. Clin Rev Allergy Immunol. 2018; 54: 52-67.

21. Patel S, Rauf A, Khan H, Meher BR, Hassan SSU. A holistic review on the autoimmune disease vitiligo with emphasis on the causal factors. Biomed Pharmacother. 2017; 92: 501-508. Available from: http://dx.doi.org/10.1016/j.biopha.2017.05.095

22. Manolache L, Benea V. Stress in patients with alopecia areata and vitiligo. J Eur Acad Dermatol Venereol. 2007; 21: 921-928.

23. Strassner JP, Harris JE. Understanding mechanisms of autoimmunity through translational research in vitiligo. Curr Opin Immunol. 2016; 43: 81-88. Available from: http://dx.doi.org/10.1016/j.coi.2016.09.008

24. Colucci R, Dragoni F, Moretti S. Oxidative stress and immune system in vitiligo and thyroid diseases. Oxid Med Cell Longev. 2015;2015:631927.

25. Picardo M, Taieb A, editors. Vitiligo. London: Springer; 2010.

26. Le Poole IC, Luiten RM. Autoimmune etiology of generalized vitiligo. Curr Dir Autoimmun. 2008; 10: 227-243.

27. Manga $P$, Elbuluk N, Orlow SJ. Recent advances in understanding vitiligo. F1000Res. 2016; 5: F1000 Faculty Rev-2234. Available from: https://f1000research.com/articles/5-2234/v1

28. Spritz RA. Shared genetic relationships underlying generalized vitiligo and autoimmune thyroid disease. Thyroid. 2010; 20: 745-754.

29. van Geel NA, Mollet IG, De Schepper S, Tjin EP, Vermaelen K, Clark RA et al. First histopathological and immunophenotypic analysis of early dynamic events in a patient with segmental vitiligo associated with halo nevi. Pigment Cell Melanoma Res. 2010; 23: 375-384.

30. Rashighi M, Harris JE. Vitiligo pathogenesis and emerging treatments. Dermatol Clin. 2017; 35: 257-265. Available from: http://dx.doi. org/10.1016/j.det.2016.11.014

31. Nicolaidou E, Mastraftsi S, Tzanetakou V, Rigopoulos D. Childhood vitiligo. Am J Clin Dermatol. 2019;20:515-526. Available from: https:// doi.org/10.1007/s40257-019-00430-0

32. Dell'Anna ML, Cario-André M, Bellei B, Taieb A, Picardo M. In vitro research on vitiligo: strategies, principles, methodological options and common pitfalls. Exp Dermatol. 2012; 21: 490-496.

33. Le Poole IC, Mehrotra S. Replenishing regulatory T cells to halt depigmentation in vitiligo. J Investig Dermatol Symp Proc. 2017; 18: S38-S45. Available from: https://doi.org/10.1016/j.jisp.2016.10.023

34. Spritz RA. Recent progress in the genetics of generalized vitiligo. $J$ Genet Genomics. 2011; 38: 271-278. Available from: http://dx.doi. org/10.1016/j.jgg.2011.05.005

35. Bunney PE, Zink AN, Holm AA, Billington CJ, Kotz CM. Orexin activation counteracts decreases in nonexercise activity thermogenesis (NEAT) caused by high-fat diet. Physiol Behav. 2017; 176: 139-148.

36. Czajkowski R, Mecinska-Jundzill K. Current aspects of vitiligo genetics. Postepy Dermatol Alergol. 2014; 31: 247-255.

37. Jin Y, Birlea SA, Fain PR, Gowan K, Riccardi SL, Holland PJ et al. Genome-wide analysis identifies a quantitative trait locus in the MHC class II region associated with generalized vitiligo age of onset. $J$ Invest Dermatol. 2011; 131: 1308-1312.

38. Jin Y, Mailloux CM, Gowan K, Riccardi SL, LaBerge G, Bennett DC et al. NALP1 in vitiligo-associated multiple autoimmune disease. $N$ Engl J Med. 2007; 356: 1216-1225.

39. Birlea SA, Jin Y, Bennett DC, Herbstman DM, Wallace MR, McCormack WT et al. Comprehensive association analysis of candidate genes for generalized vitiligo supports XBP1, FOXP3, and TSLP. J Invest Dermatol. 2011; 131: 371-381.

40. Spritz RA. The genetics of generalized vitiligo: autoimmune pathways and an inverse relationship with malignant melanoma. Genome Med. 2010; $2: 78$ 
41. Spritz RA. Six decades of vitiligo genetics: genome-wide studies provide insights into autoimmune pathogenesis. J Invest Dermatol. 2012; 132: 268-273.

42. Rork JF, Rashighi M, Harris JE. Understanding autoimmunity of vitiligo and alopecia areata. Curr Opin Pediatr. 2016; 28: 463-469.

43. Jin Y, Andersen GHL, Santorico SA, Spritz RA. Multiple functional variants of $\mathrm{IFIH1}$, a gene involved in triggering innate immune responses, protect against vitiligo. J Invest Dermatol. 2017; 137: 522-524.

44. Levy C, Khaled M. Ecad vitiliGONE. Pigment Cell Melanoma Res. 2015; 28: 376-377.

45. Xie H, Zhou F, Liu L, Zhu G, Li Q, Li C et al. Vitiligo: how do oxidative stress-induced autoantigens trigger autoimmunity? J Dermatol Sci. 2016; 81: 3-9. Available from: http://dx.doi.org/10.1016/j. jdermsci.2015.09.003

46. Chen JJ, Huang W, Gui JP, Yang S, Zhou FS, Xiong QG etal. A novel linkage to generalized vitiligo on 4q13-q21 identified in a genomewide linkage analysis of Chinese families. Am J Hum Genet. 2005; 76: 1057-1065.

47. Ren Y, Yang S, Xu S, Gao M, Huang W, Gao T et al. Genetic variation of promoter sequence modulates XBP1 expression and genetic risk for vitiligo. PLoS Genet. 2009; 5: e1000523.

48. Acosta-Alvear D, Zhou Y, Blais A, Tsikitis M, Lents NH, Arias C et al. XBP1 controls diverse cell type- and condition-specific transcriptional regulatory networks. Mol Cell. 2007; 27: 53-66.

49. Boissy RE, Spritz RA. Frontiers and controversies in the pathobiology of vitiligo: separating the wheat from the chaff. Exp Dermatol. 2009; 18: 583-585.

50. Guerra L, Dellambra E, Brescia S, Raskovic D. Vitiligo: pathogenetic hypotheses and targets for current therapies. Curr Drug Metab. 2010; 11: $451-467$.

51. lannella G, Greco A, Didona D, Didona B, Granata G, Manno A et al. Vitiligo: pathogenesis, clinical variants and treatment approaches. Autoimmun Rev. 2016; 15: 335-343. Available from: http://dx.doi. org/10.1016/j.autrev.2015.12.006

52. Picardo M, Bastonini E. A new view of vitiligo: looking at normalappearing skin. J Invest Dermatol. 2015; 135: 1713-1714. Available from: http://dx.doi.org/10.1038/jid.2015.92

53. Jimbow K, Chen H, Park JS, Thomas PD. Increased sensitivity of melanocytes to oxidative stress and abnormal expression of tyrosinase-related protein in vitiligo. Br J Dermatol. 2001; 144: 55-65.

54. Bishnoi A, Parsad D. Clinical and molecular aspects of vitiligo treatments. Int J Mol Sci. 2018; 19: 1509.

55. Tobin DJ, Swanson NN, Pittelkow MR, Peters EM, Schallreuter KU. Melanocytes are not absent in lesional skin of long duration vitiligo. J Pathol. 2000; 191: 407-416.

56. Yildirim M, Baysal V, Inaloz HS, Can M. The role of oxidants and antioxidants in generalized vitiligo at tissue level. J Eur Acad Dermatol Venereol. 2004; 18: 683-686.

57. Maresca V, Roccella M, Roccella F, Camera E, Del Porto G, Passi $S$ et al. Increased sensitivity to peroxidative agents as a possible pathogenic factor of melanocyte damage in vitiligo. J Invest Dermatol. 1997; 109: 310-313.

58. Richmond JM, Frisoli ML, Harris JE. Innate immune mechanisms in vitiligo: danger from within. Curr Opin Immunol. 2013; 25: 676-682. Available from: http://dx.doi.org/10.1016/j.coi.2013.10.010
59. Puri N, Mojamdar M, Ramaiah A. In vitro growth characteristics of melanocytes obtained from adult normal and vitiligo subjects. J Invest Dermatol. 1987; 88: 434-438.

60. Zailaie MZ. Epidermal hydrogen peroxide is not increased in lesional and non-lesional skin of vitiligo. Arch Dermatol Res. 2017; 309: 31-42.

61. Shi MH, WuY, Li L, Cai YF, Liu M, Gao XH et al. Meta-analysis of the association between vitiligo and the level of superoxide dismutase or malondialdehyde. Clin Exp Dermatol. 2017; 42: 21-29.

62. Xiao BH, Shi M, Chen H, Cui S, Wu Y, Gao XH et al. Glutathione peroxidase level in patients with vitiligo: a meta-analysis. Biomed Res Int. 2016; 2016: 3029810. doi: 10.1155/2016/3029810.

63. Hann SK, Nordlund J. Vitiligo: a monograph on basic and clinical science. Oxford: Blackwell Science; 2000. pp. 137-141.

64. Morrone A, Picardo M, de Luca C, Terminali O, Passi S, Ippolito F. Catecholamines and vitiligo. Pigment Cell Res. 1992; 5: 65-69.

65. Wood JM, Schallreuter KU. Studies on the reactions between human tyrosinase, superoxide anion, hydrogen peroxide and thiols. Biochim Biophys Acta. 1991; 1074: 378-385. doi: 10.1016/03044165(91)90088-x. PMID: 1653610.

66. Camara-Lemarroy CR, Salas-Alanis JC. The role of tumor necrosis factor- $\alpha$ in the pathogenesis of vitiligo. Am J Clin Dermatol. 2013; 14: 343-350.

67. Wang Y, Li S, Li C. Perspectives of new advances in the pathogenesis of vitiligo: from oxidative stress to autoimmunity. Med Sci Monit. 2019; 25: 1017-1023.

68. Laddha NC, Dwivedi M, Mansuri MS, Gani AR, Ansarullah M, Ramachandran AV et al. Vitiligo: interplay between oxidative stress and immune system. Exp Dermatol. 2013; 22: 245-250.

69. Rezaei N, Gavalas NG, Weetman AP, Kemp EH. Autoimmunity as an aetiological factor in vitiligo. J Eur Acad Dermatol Venereol. 2007; 21: 865-876.

70. Jin Y, Birlea SA, Fain PR, Gowan K, Riccardi SL, Holland PJ et al. Variant of TYR and autoimmunity susceptibility loci in generalized vitiligo. N Engl J Med. 2010; 362: 1686-1697.

71. Kang $P$, Zhang W, Chen X, Yi X, Song P, Chang $Y$ et al. TRPM2 mediates mitochondria-dependent apoptosis of melanocytes under oxidative stress. Free Radic Biol Med. 2018; 126: 259-268. Available from: https://doi.org/10.1016/j.freeradbiomed.2018.08.022

72. Boissy RE, LiuYY, Medrano EE, Nordlund JJ. Structural aberration of the rough endoplasmic reticulum and melanosome compartmentalization in long-term cultures of melanocytes from vitiligo patients. J Invest Dermatol. 1991; 97: 395-404.

73. Eletto D, Chevet E, Argon Y, Appenzeller-Herzog C. Redox controls UPR to control redox. J Cell Sci. 2014; 127: 3649-3658.

74. Zhang Y, Liu L, Jin L, Yi X, Dang E, Yang Y et al. Oxidative stress-induced calreticulin expression and translocation: new insights into the destruction of melanocytes. J Invest Dermatol. 2014; 134: 183-191. Available from: http://dx.doi.org/10.1038/ jid.2013.268

75. Wagner RY, Luciani F, Cario-André M, Rubod A, Petit V, Benzekri L et al. Altered E-cadherin levels and distribution in melanocytes precede clinical manifestations of vitiligo. J Invest Dermatol. 2015; 135: 1810-1819.

76. Tang A, Eller MS, Hara M, Yaar M, Hirohashi S, Gilchrest BA. $\mathrm{E}$-cadherin is the major mediator of human melanocyte adhesion to keratinocytes in vitro. J Cell Sci. 1994; 107: 983-992 
77. Rotzer V, Hartlieb E, Vielmuth F, Gliem M, Spindler V, Waschke J. E-cadherin and Src associate with extradesmosomal Dsg3 and modulate desmosome assembly and adhesion. Cell Mol Life Sci. 2015; 72: 4885-4897.

78. Roskoski R Jr. Src protein-tyrosine kinase structure, mechanism, and small molecule inhibitors. Pharmacol Res. 2015; 94: 9-25. Available from: http://dx.doi.org/10.1016/j.phrs.2015.01.003

79. Gayrard C, Bernaudin C, Déjardin T, Seiler C, Borghi N. Src- and confinement-dependent FAK activation causes $\mathrm{E}$-cadherin relaxation and $\beta$-catenin activity. J Cell Biol. 2018; 217: 1063-1077.

80. Delmas V, Larue L. Molecular and cellular basis of depigmentation in vitiligo patients. Exp Dermatol. 2019; 28: 662-666.

81. Reichert Faria A, Jung JE, Silva de Castro CC, de Noronha L. Reduced immunohistochemical expression of adhesion molecules in vitiligo skin biopsies. Pathol Res Pract. 2017; 213: 199-204. Available from: http://dx.doi.org/10.1016/j.prp.2016.12.019

82. Schallreuter KU, Wood JM, Ziegler I, Lemke KR, Pittelkow MR, Lindsey $\mathrm{NJ}$ et al. Defective tetrahydrobiopterin and catecholamine biosynthesis in the depigmentation disorder vitiligo. Biochim Biophys Acta. 1994; 1226: 181-192.

83. Filipp FV, Birlea S, Bosenberg MW, Brash D, Cassidy PB, Chen S et al. Frontiers in pigment cell and melanoma research. Pigment Cell Melanoma Res. 2018; 31: 728-735. doi: 10.1111/pcmr.12728.

84. Elela MA, Hegazy RA, Fawzy MM, Rashed LA, Rasheed H. Interleukin 17, interleukin 22 and FoxP3 expression in tissue and serum of nonsegmental vitiligo: a case- controlled study on eighty-four patients. Eur J Dermatol. 2013; 23: 350-355.

85. Basak PY, Adiloglu AK, Ceyhan AM, Tas T, Akkaya VB. The role of helper and regulatory $T$ cells in the pathogenesis of vitiligo. $J$ Am Acad Dermatol. 2009; 60: 256-260. Available from: http://dx.doi. org/10.1016/j.jaad.2008.09.048

86. Wang CQ, Cruz-Inigo AE, Fuentes-Duculan J, Moussai D, Gulati N, Sullivan-Whalen $M$ et al. Th17 cells and activated dendritic cells are increased in vitiligo lesions. PLoS One. 2011; 6: e18907.

87. Wang CQF, Akalu YT, Suarez-Farinas M, Gonzalez J, Mitsui H, Lowes MA et al. IL-17 and TNF synergistically modulate cytokine expression while suppressing melanogenesis: potential relevance to psoriasis. $J$ Invest Dermatol. 2013; 133: 2741-2752. Available from: http://dx.doi. org/10.1038/jid.2013.237

88. Parsad D, Pandhi R, Juneja A. Effectiveness of oral Ginkgo biloba in treating limited, slowly spreading vitiligo. Clin Exp Dermatol. 2003; 28 : 285-287.

89. Dell'Anna ML, Mastrofrancesco A, Sala R, Venturini M, Ottaviani M, Vidolin AP et al. Antioxidants and narrow band-UVB in the treatment of vitiligo: a double-blind placebo controlled trial. Clin Exp Dermatol. 2007; 32: 631-636.

90. Middelkamp-Hup MA, Bos JD, Rius-Diaz F, Gonzalez S, Westerhof W. Treatment of vitiligo vulgaris with narrow-band UVB and oral Polypodium leucotomos extract: a randomized double-blind placebo-controlled study. J Eur Acad Dermatol Venereol. 2007; 21: $942-950$.

91. Singh A, Kanwar AJ, Parsad D, Mahajan R. Randomized controlled study to evaluate the effectiveness of dexamethasone oral minipulse therapy versus oral minocycline in patients with active vitiligo vulgaris. Indian J Dermatol Venereol Leprol. 2014; 80: 29-35.
92. Song X, Xu A, Pan W, Wallin B, Kivlin R, Lu S et al. Minocycline protects melanocytes against $\mathrm{H} 2 \mathrm{O} 2$-induced cell death via JNK and p38 MAPK pathways. Int J Mol Med. 2008; 22: 9-16.

93. Konigsberg FM. Nrf2: La historia de un nuevo factor de transcripción que responde a estrés oxidativo. Rev Educ Bioquimica. 2007;26: $18-25$.

94. Song P, Li K, Liu L, Wang X, Jian Z, Zhang W et al. Genetic polymorphism of the Nrf2 promoter region is associated with vitiligo risk in Han Chinese populations. J Cell Mol Med. 2016; 20: 1840-1850.

95. Chang Y, Li S, Guo W, Yang Y, Zhang W, Zhang Q et al. Simvastatin Protects Human Melanocytes from H2O2-Induced Oxidative Stress by Activating Nrf2. J Invest Dermatol. 2017; 137: 1286-1296. Available from: http://dx.doi.org/10.1016/j.jid.2017.01.020

96. Jian Z, Li K, Song P, Zhu G, Zhu L, Cui T et al. Impaired activation of the Nrf2-ARE signaling pathway undermines $\mathrm{H} 2 \mathrm{O} 2$-induced oxidative stress response: a possible mechanism for melanocyte degeneration in vitiligo. J Invest Dermatol. 2014; 134: 2221-2230. Available from: http://dx.doi.org/10.1038/jid.2014.152

97. Richmond JM, Frisoli ML, Harris JE. Innate immune mechanisms in vitiligo: danger from within. Curr Opin Immunol. 2013; 25: 676-682. Available from: http://dx.doi.org/10.1016/j.coi.2013.10.010

98. van den Boorn JG, Picavet DI, van Swieten PF, van Veen HA, Konijnenberg D, van Veelen PA et al. Skin-depigmenting agent monobenzone induces potent T-cell autoimmunity toward pigmented cells by tyrosinase haptenation and melanosome autophagy. $J$ Invest Dermatol. 2011; 131: 1240-1251. Available from: http://dx.doi. org/10.1038/jid.2011.16

99. Denman CJ, McCracken J, Hariharan V, Klarquist J, Oyarbide-Valencia $\mathrm{K}$, Guevara-Patiño JA et al. HSP70i accelerates depigmentation in a mouse model of autoimmune vitiligo. J Invest Dermatol. 2008; 128 : 2041-2048.

100. Mosenson JA, Zloza A, Nieland JD, Garrett-Mayer E, Eby JM, Huelsmann EJ et al. Mutant HSP70 reverses autoimmune depigmentation in vitiligo. Sci Transl Med. 2013; 5: 174ra28.

101. Mosenson JA, Zloza A, Klarquist J, Barfuss AJ, Guevara-Patino JA, Poole IC. HSP70i is a critical component of the immune response leading to vitiligo. Pigment Cell Melanoma Res. 2012; 25: 88-98. doi: 10.1111/j.1755-148x.2011.00916.x

102. Mosenson JA, Flood K, Klarquist J, Eby JM, Koshoffer A, Boissy RE et al. Preferential secretion of inducible HSP70 by vitiligo melanocytes under stress. Pigment Cell Melanoma Res. 2014; 27: 209-220.

103. Jacquemin C, Rambert J, Guillet S, Thiolat D, Boukhedouni N, Doutre MS et al. Heat shock protein 70 potentiates interferon alpha production by plasmacytoid dendritic cells: relevance for cutaneous lupus and vitiligo pathogenesis. Br J Dermatol. 2017; 177: 1367-1375.

104. Vázquez MB, Sureda M, Rebollo J. Dendritic cells I: basic biology and functions. Inmunologia. 2012; 31:21-30.

105. Kumar R, Herbert PE, Warrens AN. An introduction to death receptors in apoptosis. Int J Surg. 2005; 3: 268-277.

106. Bhardwaj S, Rani S, Srivastava N, Kumar R, Parsad D. Increased systemic and epidermal levels of IL-17A and IL-1 $\beta$ promotes progression of non-segmental vitiligo. Cytokine. 2017; 91: 153-161. Available from: http://dx.doi.org/10.1016/j.cyto.2016.12.014

107. Mesa-Villanueva M, Patiño PJ. Receptores tipo Toll: entre el reconocimiento de lo no propio infeccioso y las señales endógenas de peligro. Inmunologia. 2006; 25: 115-130. 
108. Hemmi H, Takeuchi O, Kawai T, Kaisho T, Sato S, Sanjo H et al. A Toll-like receptor recognizes bacterial DNA. Nature. 2000; 408: 740-745.

109. Heil F, Hemmi H, Hochrein H, Ampenberger F, Kirschning C, Akira $S$ et al. Species-specific recognition of single-stranded RNA via tolllike receptor 7 and 8. Science. 2004; 303: 1526-1529. doi: 10.1126/ science. 1093620

110. Alexopoulou L, Holt AC, Medzhitov R, Flavell RA. Recognition of double-stranded RNA and activation of NF-kappaB by Toll-like receptor 3. Nature. 2001; 413: 732-738.

111. Kerur N, Veettil MV, Sharma-Walia N, Bottero V, Sadagopan S, Otageri $\mathrm{P}$ et al. IFl16 acts as a nuclear pathogen sensor to induce the inflammasome in response to Kaposi Sarcoma-associated herpesvirus infection. Cell Host Microbe. 2011; 9: 363-375. doi: 10.1016/j.chom.2011.04.008.

112. Hornung V, Ablasser A, Charrel-Dennis M, Bauernfeind F, Horvath G, Caffrey DR et al. AIM2 recognizes cytosolic dsDNA and forms a caspase-1-activating inflammasome with ASC. Nature. 2009; 458: 514-518. Available from: http://dx.doi.org/10.1038/nature07725

113. Schroder K, Tschopp J. The inflammasomes. Cell. 2010; 140: 821-832.

114. Marie J, Kovacs D, Pain C, Jouary T, Cota C, Vergier B et al. Inflammasome activation and vitiligo/nonsegmental vitiligo progression. Br J Dermatol. 2014; 170: 816-823.

115. Ferrari SM, Fallahi P, Santaguida G, Virili C, Ruffilli I, Ragusa F et al. Circulating CXCL10 is increased in non-segmental vitiligo, in presence or absence of autoimmune thyroiditis. Autoimmun Rev. 2017; 16: 946-950.

116. Kemp EH, Gavalas NG, Gawkrodger DJ, Weetman AP. Autoantibody responses to melanocytes in the depigmenting skin disease vitiligo. Autoimmun Rev. 2007; 6: 138-142.

117. Le Poole IC, van den Wijngaard RM, Westerhof W, Das PK. Presence of $T$ cells and macrophages in inflammatory vitiligo skin parallels melanocyte disappearance. Am J Pathol. 1996; 148: 1219-1228.

118. Zhang XD, Nguyen T, Thomas WD, Sanders JE, Hersey P. Mechanisms of resistance of normal cells to TRAIL induced apoptosis vary between different cell types. FEBS Lett. 2000; 482: 193-199.

119. Dwivedi M, Kemp EH, Laddha NC, Mansuri MS, Weetman AP, Begum R. Regulatory $T$ cells in vitiligo: implications for pathogenesis and therapeutics. Autoimmun Rev. 2015; 14: 49-56. Available from: http:// dx.doi.org/10.1016/j.autrev.2014.10.002

120. Taher ZA, Lauzon G, Maguiness S, Dytoc MT. Analysis of interleukin-10 levels in lesions of vitiligo following treatment with topical tacrolimus. Br J Dermatol. 2009; 161: 654-659.

121. Reviews A, Pintelaan D. Autoimmunity Reviews. 2014.

122. Harris JE, Harris TH, Weninger W, Wherry EJ, Hunter CA, Turka LA. A mouse model of vitiligo with focused epidermal depigmentation requires IFN- $\gamma$ for autoreactive CD8 T-cell accumulation in the skin. J Invest Dermatol. 2012; 132: 1869-1876. Available from: http://dx.doi. org/10.1038/jid.2011.463

123. Antonelli A, Ferrari SM, Fallahi P. The role of the Th1 chemokine CXCL10 in vitiligo. Ann Transl Med. 2015; 3: S16.

124. Rashighi M, Agarwal P, Richmond JM, Harris TH, Dresser K, Su MW etal. CXCL10 is critical for the progression and maintenance of depigmentation in a mouse model of vitiligo. Sci Transl Med. 2014; 6: 223ra23.
125. Santaguida MG, Del Duca SC, Virili C, Gargano L, Centanni M. The presence of non-segmental vitiligo modifies intracellular cytokine subsets in patients with chronic lymphocytic thyroiditis. Int J Immunopathol Pharmacol. 2010; 23: 1203-1209.

126. Ogg GS, Dunbar PR, Romero P, Chen JL, Cerundolo V. High frequency of skin-homing melanocyte-specific cytotoxic $T$ lymphocytes in autoimmune vitiligo. J Exp Med. 1998; 188: 1203-1208.

127. van den Boorn JG, Konijnenberg D, Dellemijn TA, van der Veen JP, Bos JD, Melief CJ et al. Autoimmune destruction of skin melanocytes by perilesional T cells from vitiligo patients. J Invest Dermatol. 2009; 129: 2220-2232. Available from: http://dx.doi.org/10.1038/jid.2009.32

128. Wankowicz-Kalinska A, van den Wijngaard RM, Tigges BJ, Westerhof W, Ogg GS, Cerundolo V et al. Immunopolarization of CD4+ and CD8+ $T$ cells to type-1-like is associated with melanocyte loss in human vitiligo. Lab Invest. 2003; 83: 683-695.

129. Lili Y, Yi W, Ji Y, Yue S, Weimin S, Ming L. Global activation of CD8+ cytotoxic T lymphocytes correlates with an impairment in regulatory $T$ cells in patients with generalized vitiligo. PLoS One. 2012; 7: e37513.

130. Lang KS, Caroli CC, Muhm A, Wernet D, Moris A, Schittek B et al. HLA-A2 restricted, melanocyte-specific CD8(+) T lymphocytes detected in vitiligo patients are related to disease activity and are predominantly directed against MelanA/MART1. J Invest Dermatol. 2001; 116: 891-897.

131. Palermo B, Campanelli R, Garbelli S, Mantovani S, Lantelme E, Brazzelli $V$ et al. Specific cytotoxic $T$ lymphocyte responses against Melan-A/MART1, tyrosinase and gp100 in vitiligo by the use of major histocompatibility complex/peptide tetramers: the role of cellular immunity in the etiopathogenesis of vitiligo. J Invest Dermatol. 2001; 117:326-332.

132. Mandelcorn-Monson RL, Shear NH, Yau E, Sambhara S, Barber BH, Spaner D et al. Cytotoxic T lymphocyte reactivity to gp100, MelanA/ MART-1, and tyrosinase, in HLA-A2-positive vitiligo patients. J Invest Dermatol. 2003; 121: 550-556.

133. Adams S, Lowes MA, O'Neill DW, Schachterle S, Romero P, Bhardwaj $N$. Lack of functionally active Melan-A(26-35)-specific T cells in the blood of HLA-A2 $\beta$ vitiligo patients. J Invest Dermatol. 2008; 128 : 1977e80.

134. Zhou L, Shi YL, Li K, Hamzavi I, Gao TW, Huggins RH et al. Increased circulating Th17 cells and elevated serum levels of TGF-beta and IL-21 are correlated with human non-segmental vitiligo development. Pigment Cell Melanoma Res. 2015; 28: 324-329. doi: 10.1111/ pcmr.12355.

135. Naughton GK, Eisinger M, Bystryn JC. Antibodies to normal human melanocytes in vitiligo. J Exp Med. 1983; 158: 246-251.

136. Naughton GK, Reggiardo D, Bystryn JC. Correlation between vitiligo antibodies and extent of depigmentation in vitiligo. $\mathrm{J} \mathrm{Am} \mathrm{Acad}$ Dermatol. 1986; 15: 978-981.

137. Harning R, Cui J, Bystryn JC. Relation between the incidence and level of pigment cell antibodies and disease activity in vitiligo. J Invest Dermatol. 1991; 97: 1078-1080. doi: 10.1111/1523-1747.ep12492607.

138. Cui J, Harning R, Henn M, Bystryn JC. Identification of pigment cell antigens defined by vitiligo antibodies. J Invest Dermatol. 1992; 98: 162-165. doi: 10.1111/1523-1747.ep12555773.

139. Zúñiga-Rosales Y, González-Herrera Y, Miyares-Díaz E, RodríguezPelier CV. Vitíligo: hipótesis autoinmune. Rev Biomed. 2014; 25: 145155. 
140. Englaro W, Bahadoran P, Bertolotto C, Busca R, Dérijard B, Livolsi A et al. Tumor necrosis factor alpha-mediated inhibition of melanogenesis is dependent on nuclear factor kappa B activation. Oncogene. 1999; 18: 1553-1559.

141. Wang S, Zhou M, Lin F, Liu D, Hong W, Lu L et al. Interferon- $\gamma$ induces senescence in normal human melanocytes. PLoS One. 2014; 9: e93232.

142. Gregg RK, Nichols L, Chen Y, Lu B, Engelhard VH. Mechanisms of spatial and temporal development of autoimmune vitiligo in tyrosinase-specific TCR transgenic mice. J Immunol. 2010; 184: 1909-1917.

143. Webb KC, Tung R, Winterfield LS, Gottlieb AB, Eby JM, Henning $S W$ et al. Tumour necrosis factor- $\alpha$ inhibition can stabilize disease in progressive vitiligo. Br J Dermatol. 2015; 173: 641-650.

144. Yang L, Wei Y, Sun Y, Shi W, Yang J, Zhu L et al. Interferon-gamma inhibits melanogenesis and induces apoptosis in melanocytes: a pivotal role of CD8+ cytotoxic T lymphocytes in vitiligo. Acta Derm Venereol. 2015; 95: 664-670.

145. Chatterjee S, Eby JM, Al-Khami AA, Soloshchenko M, Kang HK, Kaur $\mathrm{N}$ et al. A quantitative increase in regulatory $\mathrm{T}$ cells controls development of vitiligo. J Invest Dermatol. 2014; 134: 1285-1294. Available from: http://dx.doi.org/10.1038/jid.2013.540

146. Richmond JM, Masterjohn E, Chu R, Tedstone J, Youd ME, Harris JE. CXCR3 depleting antibodies prevent and reverse vitiligo in mice. J Invest Dermatol. 2017; 137: 982-985. Available from: http://dx.doi. org/10.1016/j.jid.2016.10.048

147. Craiglow BG, King BA. Tofacitinib citrate for the treatment of vitiligo: a pathogenesis-directed therapy. JAMA Dermatol. 2015; 151:1110-1112. doi: 10.1001/jamadermatol.2015.1520

148. Richmond JM, Bangari DS, Essien KI, Currimbhoy SD, Groom JR, Pandya $A G$ et al. Keratinocyte-derived chemokines orchestrate T-cell positioning in the epidermis during vitiligo and may serve as biomarkers of disease. J Invest Dermatol. 2017; 137: 350-358.

149. Lee AY. Role of keratinocytes in the development of vitiligo. Ann Dermatol. 2012; 24: 115-125.

150. Clark RA, Chong B, Mirchandani N, Brinster NK, Yamanaka K, Dowgiert RK et al. The vast majority of $\mathrm{CLA}+\mathrm{T}$ cells are resident in normal skin. J Immunol. 2006; 176: 4431-4439.

151. Lotti T, D'Erme AM. Vitiligo as a systemic disease. Clin Dermatol. 2014; 32: 430-434. Available from: http://dx.doi.org/10.1016/j. clindermatol.2013.11.011

152. Watanabe R, Gehad A, Yang C, Scott LL, Teague JE, Schlapbach C et al. Human skin is protected by four functionally and phenotypically discrete populations of resident and recirculating memory T cells. Sci Transl Med. 2015; 7: 279ra39.

153. Park CO, Kupper TS. The emerging role of resident memory T cells in protective immunity and inflammatory disease. Nat Med. 2015; 21: 688697.

154. Boniface K, Jacquemin C, Darrigade AS, Dessarthe B, Martins $\mathrm{C}$, Boukhedouni $\mathrm{N}$ et al. Vitiligo skin is imprinted with resident memory CD8 T cells expressing CXCR3. J Invest Dermatol. 2018; 138: 355-364. Available from: http://dx.doi.org/10.1016/j. jid.2017.08.038

155. Granata G, Greco A, lannella G, Granata M, Manno A, Savastano $E$ et al. Posterior reversible encephalopathy syndrome--Insight into pathogenesis, clinical variants and treatment approaches. Autoimmun Rev. 2015; 14: 830-836. Available from: http://dx.doi.org/10.1016/j. autrev.2015.05.006

156. Greco A, De Virgilio A, Rizzo MI, Gallo A, Magliulo G, Fusconi M et al. Microscopic polyangiitis: Advances in diagnostic and therapeutic approaches. Autoimmun Rev. 2015; 14:837-844. Available from: http:// dx.doi.org/10.1016/j.autrev.2015.05.005

157. Greco A, Gallo A, Fusconi M, Magliulo G, Turchetta R, Marinelli C et al. Cogan's syndrome: an autoimmune inner ear disease. Autoimmun Rev. 2013; 12: 396-400. Available from: http://dx.doi.org/10.1016/j. autrev.2012.07.012

158. Seneschal J, Clark RA, Gehad A, Baecher-Allan CM, Kupper TS. Human epidermal Langerhans cells maintain immune homeostasis in skin by activating skin resident regulatory T cells. Immunity. 2012; 36: 873-884.

159. Maeda Y, Nishikawa H, Sugiyama D, Ha D, Hamaguchi M, Saito T et al. Detection of self-reactive CD8 T cells with an anergic phenotype in healthy individuals. Science. 2014; 346: 1536-1540.

160. Ben Ahmed M, Zaraa I, Rekik R, Elbeldi-Ferchiou A, Kourda N, Belhadj Hmida $\mathrm{N}$ et al. Functional defects of peripheral regulatory T lymphocytes in patients with progressive vitiligo. Pigment Cell Melanoma Res. 2012; 25: 99-109.

161. Kroon MW, Vrijman C, Chandeck C, Wind BS, Wolkerstorfer A, Luiten RM et al. High prevalence of autoimmune thyroiditis in children and adolescents with vitiligo. Horm Res Paediatr. 2013; 79: 137-144.

162. Sawicki J, Siddha S, Rosen C. Vitiligo and associated autoimmune disease: retrospective review of 300 patients. J Cutan Med Surg. 2012 16: 261-266.

163. Balagula Y, Garbe C, Myskowski PL, Hauschild A, Rapoport BL, Boers-Doets $C B$ et al. Clinical presentation and management of dermatological toxicities of epidermal growth factor receptor inhibitors. Int J Dermatol. 2011; 50: 129-146.

164. Palermo B, Garbelli S, Mantovani S, Scoccia E, Da Prada GA, Bernabei $P$ et al. Qualitative difference between the cytotoxic $T$ lymphocyte responses to melanocyte antigens in melanoma and vitiligo. Eur J Immunol. 2005; 35: 3153-3162.

165. Sheth VM, GuoY, Qureshi AA. Comorbidities associated with vitiligo: a ten-year retrospective study. Dermatology. 2013; 227: 311-315.

166. Dahir AM, Thomsen SF. Comorbidities in vitiligo: comprehensive review. Int J Dermatol. 2018; 57: 1157-1164.

167. Baldini E, Odorisio T, Tuccilli C, Persechino S, Sorrenti S, Catania A et al. Thyroid diseases and skin autoimmunity. Rev Endocr Metab Disord. 2018; 19: 311-323.

168. Castanet J, Ortonne JP. Pathophysiology of vitiligo. Clin Dermatol. 1997; 15: 845-851. doi: 10.1016/s0738-081x(97)00125-9.

169. Alkhateeb A, Fain PR, Thody A, Bennett DC, Spritz RA. Epidemiology of vitiligo and associated autoimmune diseases in Caucasian probands and their families. Pigment Cell Res. 2003; 16: 208-214.

170. Cunliffe WJ, Hall R, Newell DJ, Stevenson CJ. Vitiligo, thyroid disease and autoimmunity. Br J Dermatol. 1968; 80: 135-139.

171. Amerio P, Tracanna M, De Remigis P, Betterle $C$, Vianale L, Marra ME et al. Vitiligo associated with other autoimmune diseases: polyglandular autoimmune syndrome types $3 \mathrm{~B}+\mathrm{C}$ and 4. Clin Exp Dermatol. 2006; 31: 746-749. 
172. Kemp EH, Emhemad S, Akhtar S, Watson PF, Gawkrodger DJ, Weetman AP. Autoantibodies against tyrosine hydroxylase in patients with non-segmental (generalised) vitiligo. Exp Dermatol. 2011;20:35-40.

173. Kemp EH, Gawkrodger DJ, Watson PF, Weetman AP. Immunoprecipitation of melanogenic enzyme autoantigens with vitiligo sera: evidence for cross-reactive autoantibodies to tyrosinase and tyrosinase-related protein-2 (TRP-2). Clin Exp Immunol. 1997; 109: 495-500.

174. Kemp EH, Waterman EA, Gawkrodger DJ, Watson PF, Weetman AP. Autoantibodies to tyrosinase-related protein-1 detected in the sera of vitiligo patients using a quantitative radiobinding assay. Br J Dermatol. 1998; 139: 798-805.

175. Baharav E, Merimski O, Shoenfeld Y, Zigelman R, Gilbrud B, Yecheskel $\mathrm{G}$ et al. Tyrosinase as an autoantigen in patients with vitiligo. Clin Exp Immunol. 1996; 105: 84-88.

176. Neumeister P, Strunk D, Apfelbeck U, Sill H, Linkesch W. Adoptive transfer of vitiligo after allogeneic bone marrow transplantation for non-Hodgkin's lymphoma. Lancet. 2000; 355: 1334-1335.

177. Cho SB, Roh MR, Chung KY, Lee KH, Park YK. Generalized vitiligo after allogeneic bone marrow transplantation. Acta Derm Venereol. 2005; 85: 82-83.
178. Kawakami Y, Suzuki Y, Shofuda T, Kiniwa Y, Inozume T, Dan K et al. $T$ cell immune responses against melanoma and melanocytes in cancer and autoimmunity. Pigment Cell Res. 2000; 13 Suppl 8: 163-169.

179. Yee C, Thompson JA, Roche P, Byrd DR, Lee PP, Piepkorn M et al. Melanocyte destruction after antigen-specific immunotherapy of melanoma: direct evidence of t cell-mediated vitiligo. J Exp Med. 2000; 192: $1637-1644$.

180. Dwivedi M, Laddha NC, Arora P, Marfatia YS, Begum R. Decreased regulatory T-cells and CD4(+)/CD8(+) ratio correlate with disease onset and progression in patients with generalized vitiligo. Pigment Cell Melanoma Res. 2013; 26: 586-591. doi: 10.1111/pcmr.12105.

\section{Correspondencia:}

Dr. Germán Guerrero Oliva

Centro Dermatológico «Dr. Ladislao de la Pascua». Dr. Vértiz Núm. 464, Col. Buenos Aires, Alcaldía Cuauhtémoc, 06780, Ciudad de México. E-mail: germanguerrerooliva7@gmail.com 